\section{ALCOHOL WITHDRAWAL RECOGNITION, SCREENING AND PRESCRIPTION PRACTICES IN THE ACUTE MEDICAL SETTING}

N Moran, E Jones, A O'Toole, S Patchett, G Harewood, F Murray Department of Gastroenterology and Hepatology, Beaumont Hospital, Dublin, Ireland

\subsection{6/gutjnl-2013-305143.69}

Introduction Delirium tremens (DT) is defined by hallucinations, tachycardia, hypertension, fever, agitation, and diaphoresis in the setting of acute reduction or abstinence from alcohol. DT is a medical emergency associated with a $5 \%$ mortality rate.

There are established hospital guidelines available to guide the management of alcohol withdrawal and validated screening tools available to assess and treat patients.

Aims/Background To assess practices surrounding alcohol withdrawal screening and appropriate prescribing in acute medical admissions in a University Hospital.

Method In the emergency department, we obtained details of all non-elective admissions during one week from 6th-10th February 2013. We reviewed admission notes to classify patients according to risk of alcohol withdrawal. We recorded whether alcohol consumption was recorded, if screening tools to assess for withdrawal risk were used, if withdrawal was managed appropriately and if the alcohol liaison nurse was consulted. In addition we noted if refeeding syndrome risk was monitored.

Results 110 patients were included; 57 female (52\%) and 53 male (48\%). Median age was 67 (range 19-88 years). $82.5 \%$ had alcohol consumption documented. Of these $67.5 \%$ were expressed in units per week. $8 \%(n=6)$ were identified as being at risk of alcohol withdrawal, of these $50 \%$ were treated with IV Thiamine and Chlordiazepoxide. 33\% (2/6) were referred to the alcohol liaison services. 1 patient had routine electrolyte measurement. No patients developed DT.

Conclusion $8 \%$ of all patients were at risk of alcohol withdrawal. The appropriate management and alcohol liaison referral was prescribed in less than $50 \%$. 